\title{
Silicon content of individual cells of Synechococcus from the North Atlantic Ocean
}

${ }^{1}$ Daniel C. Ohnemus, ${ }^{1}$ Sara Rauschenberg, 2,3Jeffrey W. Krause, ${ }^{4}$ Mark A. Brzezinski, ${ }^{5}$ Jackie L. Collier, ${ }^{5}$ Sabrina Geraci-Yee, ${ }^{6}$ Stephen B. Baines, ${ }^{1}$ Benjamin S. Twining

${ }^{1}$ Bigelow Laboratory for Ocean Sciences, East Boothbay, Maine, USA

${ }^{2}$ Dauphin Island Sea Lab, Dauphin Island, Alabama, USA

${ }^{3}$ Department of Marine Sciences, University of South Alabama, Alabama, USA

${ }^{4}$ Marine Science Institute and the Department of Ecology Evolution and Marine Biology, University of California, Santa Barbara, California, USA

${ }^{5}$ School of Marine and Atmospheric Sciences, Stony Brook University, Stony Brook, New York, USA

${ }^{6}$ Department of Ecology and Evolution, Stony Brook University, Stony Brook, New York, USA

keywords: silicon; Synechococcus; synchrotron x-ray fluorescence; SXRF; elemental quotas

C 2016. This manuscript version is made available under the Elsevier user license http://www.elsevier.com/open-access/userlicense/1.0/ 


\section{Abstract}

2 The widely distributed marine cyanobacterium Synechococcus is thought to exert an influence on the marine silicon (Si) cycle through its high cellular Si relative to organic content. There are few measurements of Si in natural populations of Synechococcus, however, and the degree to which Synechococcus from various oligotrophic field sites and depths accumulate the element is unknown. We used synchrotron x-ray fluorescence to measure Si quotas in individual Synechococcus cells collected during three cruises in the western North Atlantic Ocean in the summer and fall, focusing on cells from the surface mixed layer (SML; $<10 \mathrm{~m}$ ) and the deep chlorophyll maximum (DCM). Individual cell quotas varied widely, from 1 to $4700 \mathrm{amol} \mathrm{Si} \mathrm{cell}^{-1}$, though the middle $50 \%$ of quotas ranged between 17 and 119 amol Si cell ${ }^{-1}$. Mean station-specific quotas exhibited an even narrower range of 31 - $72 \mathrm{amol} \mathrm{Si} \mathrm{cell}^{-1}$. No significant differences in Si quotas were observed across cruises or among stations, and no effect of ambient silicic acid concentration on quotas was observed within the narrow range of silicic acid concentrations encountered $(0.6-1.3 \mu \mathrm{M})$. Despite this small range in ambient silicic acid, cells collected from the SML had an average of two-fold more Si than cells collected from the DCM. Differences in Si content with depth may be related to observed differences in the dominant Synechococcus clades between the SML and DCM habitats, determined by petB gene sequencing.

\section{Introduction}

Photoautotrophic picocyanobacteria from the genus Synechococcus are found in nearly all ocean surface waters and have been shown to accumulate Si. Surprisingly, they can attain biomass-normalized cellular Si:S and Si:P mole ratios that are, on average, up to $50 \%$ of those in siliceous diatoms (Baines et al. 2012). Synechococcus are most abundant in nutrient-rich upwelling systems and in coastal and estuarine environments (Partensky et al. 1999), but they are also found in oligotrophic openocean systems like the Costa Rica Dome at abundances as high as $10^{5}$ to $10^{6} \mathrm{~mL}^{-1}$ (Saito et al., 2005; Stukel et al., 2013). Persistent accumulation of Si by Synechococcus presents an additional pathway for Si uptake that is not controlled by diatoms. Furthermore, recent analyses have suggested that $\geq 75 \%$ of the euphotic zone biogenic silica (bSi) pool is "detrital" (i.e. not associated with living diatoms) (Krause et al., 2010; Marquez, 2015). Contributions by Synechococcus would have been systematically included in this detrital pool instead of within picoplankton size cells. Therefore, the direct consideration and inclusion of Synechococcus biomass may be important to accurately modelling the Si cycle in ocean regions where Synechococcus biomass is significantly higher than diatoms.

Since the discovery of Si accumulation by marine Synechococcus by Baines et al. (2012), other studies have investigated this organism's potentially outsized effects on other elemental cycles and on vertical C export. Tang et al. (2014) demonstrated accumulation of $\mathrm{Mg}$ and $\mathrm{Si}$ in the protein- and carbohydrate-rich extracellular polymeric substances (EPS) of degrading Synechococcus cultures and in water column micro-aggregates near Bermuda. Deng et al. (Deng et al., 2015b) further showed that Synechococcus detritus scavenges C from exopolymers and dissolved 
organic matter, forming rapidly sinking (440-660 $\mathrm{m} \mathrm{d}^{-1}$ ) aggregates that may export

$482-3$ times more C than in Synechococcus cells alone. Recent results from the Tara oceans expedition have implicated Synechococcus and its phages as having central, strategic roles in C export networks of the oligotrophic gyres (Guidi et al., 2016). Scavenging and vertical export by Synechococcus biomass thus appears to be more significant to a range of elemental budgets than previously thought (Lomas et al., 2010).

The Synechococcus genus has wide temperature, nutrient, and light tolerances due to its considerable genetic diversity. Numerous clades have been defined using genetic techniques, and many clades show preferences for specific marine niches (Tai, 2009) though little is known about the degree to which natural field populations accumulate Si. With the abundance and geographic range of Synechococcus expected to grow in response to global climate change (Flombaum et al., 2013), their influence on the marine Si cycle and other elemental cycles may also grow. The observed expansion of the oligotrophic gyres (Polovina et al., 2008) and decadal declines in open-ocean diatom biomass (Krause et al., 2009) underscore the importance of understanding the interactions of natural field Synechococcus populations with Si. How do typical Synechococcus cellular Si quotas (i.e. mol Si per cell) vary across environments, seasons, and within various marine niches (e.g. surface mixed layer [SML], deep chlorophyll maximum [DCM])? We investigated these questions through synchrotron $\mathrm{x}$-ray fluorescence (SXRF)-based examination of single-cell elemental quotas in field-collected Synechococcus during the summer and early fall in the western North Atlantic.

\section{Methods}

Bottle sampling: BATS and BVAL cruises

Whole seawater samples were collected during Bermuda Atlantic Time Series (BATS) cruises in July, 2012 (BATS cruise 283) and October, 2012 (BATS 286) and during a BATS validation cruise in September-October, 2013 (BVAL 48; stn. 2) on the $R / V$ Atlantic Explorer [Fig.1]. The BVAL cruise then continued south towards Puerto Rico, occupying several stations from which only SML samples were analyzed. Seawater was collected from the SML (5 - $10 \mathrm{~m}$ sampling depth) and the depth of the subsurface DCM (75 - 88m sampling depth; determined for each cast via in situ fluorometry) using the ship's CTD rosette. All reported parameters were measured on water collected from the same bottles. For single-cell SXRF mapping, whole seawater was preserved with glutaraldehyde at a final concentration of $0.25 \%$ and cells were deposited on Au electron microscopy grids using centrifugation at $1700 \mathrm{rcf}$ for 30 minutes. Grids were briefly rinsed with deionized water to remove residual salt. Microscopy was used to locate orange-fluorescing, single Synechococcus targets for later SXRF analyses using an excitation wavelength of $480 \mathrm{~nm}$ and a long-pass emission filter. Cell size (c.a. $1 \mu \mathrm{m}$ ) and visual morphology (ovoid shape) were also used to distinguish Synechococcus cells from other auto-fluorescing cell types.

91 
92 A wide range of values were observed for several environmental parameters in part

93 due to local sampling site variability within cruises [Table 2]. This variation is likely

94 due to a combination of vessel drift and advection of eddy features past the ship's

95 position. Samples analyzed from BATS cruise 283 (July 2012) were collected during

96 two casts on sequential days. Synechococcus abundances and small bSi $(0.4-3 \mu \mathrm{m}$

97 size-fraction) were notably higher at the SML than at the DCM on cast 1, while cast 3

98 exhibited similar values for both parameters at both depths. SXRF samples from

99 BATS cruise 286 (Oct 2012) were also collected during two casts on sequential days,

100 with significantly higher DCM Synechococcus abundances on cast 3. During the BVAL

101 cruise, Synechococcus cell abundances in the SML generally increased towards the

102 south, though compared to the BATS cruises, Synechococcus cell abundances and bSi

103 were both generally lower and exhibited smaller ranges during this cruise.

104

105

106

107

108

109

110

111

112

113

114

115

116

117

118

119

120

121

122

123

124

125

126

127

128

129

130

131

132

133

134

135

136

137

\section{SXRF methodology}

Samples were analyzed at the Advanced Photon Source beamline 2-ID-E with an incident energy of $10 \mathrm{keV}$ using protocols similar to those previously described (Twining et al., 2011; 2003). Focused beam size was up to $0.4 \mu \mathrm{m}$ in the vertical and $\sim 0.8 \mu \mathrm{m}$ in the horizontal. Step sizes of $0.1 \mu \mathrm{m}$ were used to over-sample target cells and background areas. The pixels covering the cell were averaged, and the mean signal from neighboring cell-free areas was subtracted from this average. The background-corrected concentration was then multiplied by the area of the analyzed cell region, resulting in a mol cell- ${ }^{-1}$ measurement referred to herein as the cell quota.

Four detector elements collected SXRF spectra simultaneously at each pixel, and fluorescence data from each detector was quantified independently using NBS Standard 1833 and an AXO thin-film SXRF standard. Lighter elements (Si, P) that are absent in the standards were fit using a least squares linear regression through the $\log _{10}$ of expected quantum yield for the elements present in the standards, as detailed in Núñez-Milland et al. (2010).

For the picocyanobacteria analyzed in this study, slight differences in geometric orientation of the detector elements relative to the sample, combined with the shallow $15^{\circ}$ observation angle to the sample grid (which has vertical topography significantly larger than many cells) occasionally created inconsistencies in the concentrations measured by the four detector elements. Detectors generally agreed on quantifications of high atomic mass (Z) elements (e.g. Fe, Ni), but occasionally two or three detectors would measure anomalously low quantifications for the low$\mathrm{Z}$ elements ( $\mathrm{Si}, \mathrm{P}, \mathrm{S})$. We suspect that in these cases, fluorescent $\mathrm{x}$-rays emitted by target cells were being shaded by the Au grid bars or by larger nearby cells, with the effect more noticeable for low-Z elements which emit lower-energy fluorescent $\mathrm{x}$ rays that are more prone to absorption. This effect was detector-specific, implicating the geometry of the sample grid, cell region of interest, and detector position. To locate and compensate for this effect, for each mapped region of interest (ROI) and detector we plotted the measured elemental quotas (normalized to the highest detector) versus Z using MATLAB (The Mathworks Inc., Natick, MA, USA). Shaded 
detectors were identified as those that exhibited a roughly linear decrease in relative quantification at lower $Z$. Data from shaded detectors were excluded in the

\section{SXRF uncertainty calculations in lieu of detection limits}

Element-specific background levels vary from cell to cell depending on the target and its location on each grid, so that detection limits varied among runs, grids, and locations on grids. To estimate detection limits, we quantified cell ROI and background (non-cell) ROI uncertainties for each scan using the 1-sigma fitting uncertainties reported by the beamline MAPS software during elemental peakfitting of the SXRF energy spectra (Vogt, 2003). We report the median target cell ROI uncertainty \pm 1 s.d., and median target cell/background ratios in Table 1. For Si and $\mathrm{S}$, cell ROI measurements have similar uncertainties (typically less than 5\%). For P, cell ROIs have uncertainties that are typically $10-17 \%$. On average, fluorescence signals in cell ROIs were 148\% (Si), 631\% (P) and 394\% (S) of the signals in background ROIs, which themselves could be quantified with uncertainties of less than $10 \%$.

\section{Statistical Analyses}

Generalized linear modeling was performed using the software JMP®, Version 10 , SAS Institute Inc., Cary, NC. We tested the significance of cruise, station (nested within cruise, indicated by [Cruise] in Table 3) and sampling depth (i.e. SML or DCM) as fixed, independent effects on the dependent variables of $\log _{10}$-transformed cellular $\mathrm{Si}, \mathrm{P}$, and $\mathrm{S}$ quotas as well as Si:P, Si:S, and P:S quota ratios. Effects with an associated $p$-value of $<0.05$ were treated as significant and are discussed further in the text.

\section{Bulk bSi quota measurements}

In field samples, bulk biogenic silica concentration (bSi) was determined for two size fractions: $>3 \mu \mathrm{m}$ (here, "large bSi") and $0.4-3.0 \mu \mathrm{m}$ ( "small bSi") collected by sequentially filtering 2.5 to $3.0 \mathrm{~L}$ of seawater through $3.0 \mu \mathrm{m}$ and then $0.4 \mu \mathrm{m}$ polycarbonate filters ( $47 \mathrm{~mm}$ diameter). Filters were folded into quarters, placed in cryogenic vials, dried at $60^{\circ} \mathrm{C}$, and sealed until analysis on shore in Teflon tubes. Both bSi and lithogenic silica were quantified from the same sample using the procedure of Brzezinski and Nelson (1995). Because some lithogenic silica can dissolve during $\mathrm{NaOH}$ digestion, we corrected $\mathrm{bSi}$ values by subtracting $15 \%$ of the measured lithogenic concentration, an empirically determined maximum correction factor for marine samples (Ragueneau and Tréguer 1994).

\section{Flow cytometric enumeration of Synechococcus}

Quantification of Synechococcus by flow cytometry followed the general procedure of Collier and Palenik (2003). Briefly, duplicate $1.5 \mathrm{~mL}$ subsamples of raw seawater were preserved as quickly as possible after collection at a final concentration of $0.25 \%$ EM-grade glutaraldehyde, incubated in the dark for 30 minutes at room temperature, and then frozen at $-80^{\circ} \mathrm{C}$ until analysis on a four-color FACSCalibur (BD Biosciences, San Jose, CA, USA) flow cytometer for 10 to 15 minutes at a flow rate of 
$1 \mu \mathrm{L} \mathrm{s}^{-1}$ with detectors set to an appropriate gain and a log scale. As an internal standard, 10,000 fluorescent beads (Polysciences Fluorescbrite PlainYG, $1.0 \mu \mathrm{m}$ diameter) were added to $1 \mathrm{~mL}$ of each sample just before analysis. List-mode data files were imported into FlowJo (v6; Ashland, OR, USA) and groups of signals representing Synechococcus were identified and enumerated by their fluorescence and scatter characteristics.

\section{Cyanobacterial community structure}

Particles were collected from 1.5 to 2 liters of seawater in two size fractions as described for bulk $\mathrm{Si}$, and total DNA was extracted from the $0.4-\mu \mathrm{m}$ fraction using the PowerSoil DNA Isolation Kit (MO BIO, Carlsbad, CA, USA) according to the manufacturer's instructions. Oligonucleotide primers modified from Mazard et al. (2012) were designed to amplify a 514 basepair region of all known marine Synechococcus and Prochlorococcus petb genes (encoding cytochrome $b_{6}$; petBf 5'TACGAYTGGTTYCARGARMG and petBr 5'-AACGTRTGRAGRCTRTARAA). For multiplexing of amplicon sequencing, ten forward and ten reverse primers, each with a distinct 16 base barcode (designed following the recommendations of Pacific Biosciences, Menlo Park, CA, USA), were synthesized by IDT (Coralville, Iowa, USA). Triplicate $20 \mu \mathrm{L}$ PCR reactions were done for each sample using 1 to $3 \mu \mathrm{L}$ of purified DNA (typically $2 \mathrm{ng}$ ), $10 \mu \mathrm{L}$ of Phusion 2X Master Mix (NEB, Ipswich, MA, USA), and $0.5 \mu \mathrm{M}$ of forward and reverse barcoded primers. The PCR conditions were initial denaturation at $94^{\circ} \mathrm{C}$ for 5 minutes, 30 cycles of 30 seconds at $94^{\circ} \mathrm{C}, 30$ seconds at $40^{\circ} \mathrm{C}$, and 45 seconds at $72^{\circ} \mathrm{C}$, followed by a final extension at $72^{\circ} \mathrm{C}$ for 10 minutes and a $4^{\circ} \mathrm{C}$ hold. The replicate PCR products were mixed, gel-purified, then quantified using Quant-iT PicoGreen dsDNA Assay Kit (Invitrogen, Waltham, MA, USA). Equal amounts of PCR product from each of ten uniquely barcoded samples were pooled and submitted to the University of Delaware Sequencing \& Genotyping Center (Newark, DE, USA) for sequencing on the Pacific Biosciences RSII Single-Molecule Sequencer using one SMRT Cell.

The raw data were processed using the SMRT Analysis software (Pacific Biosciences) with default settings. QIIME (1.9.1, implemented in Oracle VM VirtualBox 5.0.8; (Caporaso et al., 2010)) scripts were used to demultiplex the reads of insert, remove incomplete sequences lacking barcodes or primers at either end, and trim barcodes and primers from complete sequences. A reference alignment and phylogenetic tree constructed using all unique cyanobacterial pet $B$ sequences covering the full amplified region available in GenBank in November 2015 revealed that sequences were generally at least $90 \%$ identical within distinct clusters representing known clades of Synechococcus, and less than $90 \%$ identical between clusters. We therefore used the QIIME script pick_otus.py (Edgar, 2010) to place the sequences into operational taxonomic units (OTUs) at $90 \%$ sequence identity. OTUs with less than $0.01 \%$ of the total sequences were removed, and the most abundant sequence in each of the remaining OTUs was used, along with the reference alignment, for taxonomic assignment of each OTU based on sequence similarity 
chimeric sequences with both ChimeraSlayer (Haas et al., 2011) and blast_fragments (Altschul et al., 1990).

231

The representative sequences for the resulting 164 OTUs were aligned with the reference petB set using ClustalW in BioEdit 7.2.5 (Hall, 1999). A phylogenetic tree (neighbor-joining, Tamura 3-paramenter model with gamma $=1$ and unequal rates among lineages) was constructed in MEGA6 (Tamura et al., 2013) to confirm that each representative sequence grouped with one or more sequences from cultured isolates belonging to the clade, as identified by Mazard et al. (2012), to which its OTU had been assigned in QIIME (the most abundant being Synechococcus clade I, II, III, XVI, or WPC1). Two groups of OTUs were found in strongly supported but unnamed clusters, containing only environmental sequences from this and other studies (no cultivated strains); these are identified here as U1 and U2. Because of their low abundance, OTUs belonging to clades IV, V/VI/VII, or clustering with strain KORDI100 have been summed along with 4 taxonomically unassigned OTUs into 'other'. Prochlorococcus sequences, which are not the focus of this study, have been excluded from the data presented here but will be presented elsewhere.

\section{Results}

Single-cell quotas and quota ratios for Si, $P$ and $S$

Individual Synechococcus cellular quotas for Si were highly variable, ranging from 1 -4694 amol Si cell ${ }^{-1}$ [Fig. 2]. However, more than $80 \%$ of samples fell within a more moderate range of 10 and $400 \mathrm{amol} \mathrm{Si} \mathrm{cell}^{-1}$. Median and geometric mean Si quotas were 44 and $47 \mathrm{amol} \mathrm{Si} \mathrm{cell}^{-1}$, respectively, with $25 \%$ and $75 \%$ quantiles of 17 and 119 amol Si cell ${ }^{-1}$. Although cell-associated Si quotas were quite variable, cell Si SXRF peaks were indistinguishable from background abundances in only 3 of 118 Synechococcus cells analyzed: two at BVAL-2 DCM and one at BVAL-5 SML.

Generalized linear modeling [Table 3] found no significant effect of cruise or station on Si quotas [Table 3; $p>0.05$ ]. Depth, however, was found to significantly affect $\mathrm{Si}$ quota, despite no major vertical variability in dissolved silicic acid concentrations (see below). Cells from the SML had c.a. two-fold more Si than cells from the DCM; least-square geometric mean quotas for SML and DCM cells were 67 and $31 \mathrm{amol} \mathrm{Si}$ cell ${ }^{-1}$, respectively [Fig 2].

Quotas of cellular P and S-frequently used as proxies of cell biomass to compensate for natural variations in cell size, morphology, and macronutrient status (Twining et al., 2011) -were also measured using SXRF [Table 1; Fig. 2]. ( $\mathrm{C}$ and $\mathrm{N}$ are too light to be directly measured with SXRF.) Both of these essential elements showed less variability than Si. Median and geometric mean P quotas were 22 and 25 amol P cell $^{-1}$, respectively, with $25 \%$ and $75 \%$ quantiles of 14 and 32 amol P cell ${ }^{-1}$. Median and geometric mean S quotas were 47 and 55 amol S cell- ${ }^{-1}$, respectively, with $25 \%$ and $75 \%$ quantiles of 23 and 117 amol S cell- 1 .

Generalized linear modeling [Table 3] showed that cruise, but not station or depth, significantly affected P quotas; least-square geometric mean P quotas were lower 
275 during the July cruise (18 amol P cell ${ }^{-1}$ ) than the Sept/Oct cruises (BATS286: 28

276 amol P cell ${ }^{-1}$; BVAL: 40 amol P cell ${ }^{-1}$ ). All variables (cruise, station, and depth) were

277 significant factors affecting $S$ quotas; least-square geometric mean $S$ quotas were

278 higher during the July cruise (70 amol S cell- ${ }^{-1}$ ) than the Sept/Oct cruises (both: 34

$\left.279 \mathrm{amol} \mathrm{S} \mathrm{cell}^{-1}\right)$. Similar to Si, S quotas were higher in the SML (72 amol S cell ${ }^{-1}$ ) than

280 the DCM (26 amol S cell- $\left.{ }^{-1}\right)$.

281

282 Ratios of P:S varied significantly across cruises, stations, and depth, reflecting the

283

284

285

286

287

288

289

290

291

292

293

294

295

296

297

298

299

300

301

302

303

304

305

306

307

308

309

310

311

312

313

314

315

316

317

318

319

320 underlying variability in the individual elements. Ratios of P:S were lower in the SML (0.30 mol P:mol S) than at the DCM (1.29 mol P:mol S) due to S elevation in the SML, while P:S ratios were lower during the July cruise (0.29 mol P:mol S) than the Sept/Oct cruises (0.73 and $1.12 \mathrm{~mol}$ P:mol S in BATS286 and BVAL, respectively) due to lower P values during the mid-summer. Ratios of Si:S did not significantly vary across cruise, station, or depth because Si and S varied in parallel with depth. Least-square geometric mean Si:P ratios were notably higher in the SML $(2.80 \mathrm{~mol}$ Si:mol P) than at the DCM (0.63 mol Si:mol P), reflecting higher Si accumulation by SML cells.

\section{Lack of relationships between Synechococcus Si content and major environmental} parameters

Several independently measured environmental parameters, including bSi concentration, bSi size fractionation, and Synechococcus abundance, varied broadly across the three cruises. We did not observe significant relationships between these parameters and Synechococcus Si quotas [Fig. 3] (Pearson rho values +0.16 to +0.34 ; p-values all $>0.31$. Ambient dissolved $\mathrm{SiOH}_{4}$ concentrations also showed no relationship to Synechococcus cellular Si quotas (Pearson rho -0.22; p-value 0.52), although in accordance with the Sargasso Sea sampling region, only a small absolute range for this parameter $(0.6-1.3 \mu \mathrm{M})$ were encountered in upper water column Synechococcus habitats during the cruises.

\section{Clade identity of SML and DCM Synechococcus communities}

Synechococcus community assemblages within the SML and DCM were determined by pet $B$ (cytochrome $b_{6}$ ) gene sequences [Fig. 4]. Synechococcus communities from the SML were consistently dominated by OTUs representing clade III as identified by Mazard et al. (2012), with a lesser contribution of a previously unidentified clade, U1. Synechococcus communities at BATS DCM depths were more variable, showing greater contributions of clade II during the Oct. 2012 cruise (BATS286) and clades II and XVI during the July-2012 (BATS 283) cruise and the autumn BVAL cruise. Prior clade-specific niche determinations have shown that the SML-dominant clade III is considered to be an oligotrophic clade, while clade II is more broadly distributed in the tropics (Zwirglmaier et al., 2008), and clade XVI is more restricted to deep water (Ahlgren and Rocap, 2006).

\section{Discussion}

The results of this study show that measurable Si was present in nearly all Synechococcus cells analyzed, confirming that Si accumulation is a common 
phenomenon in natural cells from the oligotrophic gyres. However, Si contents were highly variable and generally uncorrelated with measured environmental variables, suggesting that less direct effects such as community structure may drive $\mathrm{Si}$ accumulation in these ecosystems.

\section{Si quotas and elevation in the SML}

Previous reports of Si accumulation by Synechococcus in natural systems are limited to one station in the equatorial Pacific and one cruise in the Sargasso Sea (Baines et al., 2012). To expand these environmental observations in the oligotrophic gyre, we collected Synechococcus cells from the BATS site near Bermuda at several times in summer and fall (July through October) and from several sites between Bermuda and Puerto Rico in early October 2013 [Fig. 1]. Si quotas reported here, while variable in range, are consistent with previously reported field Si quotas in Synechococcus from the Sargasso Sea (means: 5 - $413 \mathrm{amol} \mathrm{Si} \mathrm{cell}^{-1}$ ) (Baines et al., 2012).

Single-cell SXRF analyses focused on cells collected from two depths: the surface mixed layer (SML; 5 - $10 \mathrm{~m}$ sampling depth) and the deep chlorophyll maximum (DCM: 75 - $88 \mathrm{~m}$ sampling depth)[Table 2] across a range environmental parameters that may have relationships to cellular Si. In one of the few consistent effects on field Si accumulation, despite its wide range and the narrow range in dissolved silicic acid concentrations, cells from SML had an average of two-fold more Si than cells from the DCM. Other environmental parameters, such as higher cell abundances, may have been linked to lower Si quotas due to growth dilution, while higher bSi concentrations or small-size bSi fractionation may have directly represented higher Si quotas in small Synechococcus cells. However, none of these environmental parameters acted as a significant predictor of cellular Si content [Fig. 3] within these oligotrophic ecosystems.

The difference in Si quotas between the SML and the DCM does not appear to be due to growth dilution. While we did not directly assess Synechococcus growth rates during the cruises, pigment-based estimates of cyanobacterial growth just north of BATS at the Ocean Flux Program site have demonstrated that cyanobacterial growth rates in the summer are highest in the SML and decline with depth (Goericke, 1998). Likewise, field measurements at station ALOHA have also shown that Synechococcus growth rates are typically higher (or similar) in the SML than at the DCM (Liu et al., 1995). When grown under different light levels in culture, Synechococcus clones from four different major sub-clades (Scanlan et al., 2009) exhibited an inverse correlation between Si content and growth rate (Brzezinski et al., 2016). Thus depth-related growth rates patterns of Synechococcus cells should have resulted in higher Si contents for DCM cells than in the SML, the opposite of what was observed. It appears then that growth-rate dilution is not likely the key determinant of depthrelated differences in Si content.

Shifts in cyanobacterial community structure may be better related to the observed differences in Synechococcus Si content across depths, as Synechococcus 
assemblages did markedly differ between the SML and the DCM [Fig. 4].

368 Experiments with cultured Synechococcus have demonstrated that clone identity can be a stronger predictor of Si quota than growth rate (Brzezinski et al., 2016). Assuming the recovered sequences reflect general shifts in Synechococcus assemblage structure, we were most likely to collect SXRF data from clade III Synechococcus in SML samples and from a greater proportion of clade II, XVI, and other Synechococcus clades in DCM samples. Community variation in Si uptake or sequestration provides a possible rationale for the observed differences in $\mathrm{Si}$ content between the SML and the DCM.

\section{Variations in P and S quotas and biomass-normalization} Synechococcus $\mathrm{P}$ quotas reported here are similar to those previously reported at BATS (Twining et al. 2010; $20-51 \mathrm{amol} \mathrm{P}^{\mathrm{a}}$ cell $^{-1}$ ) and in cultured strains (Bertilsson et al. 2003, Heldal et al. 2003; $15-116$ amol $P$ cell $^{-1}$ ). $S$ quotas were also comparable to previous SXRF measurements at BATS (Twining et al. 2010; 35 - 79 amol $S$ cell- ${ }^{-1}$ ) and to electron microprobe measurements of $S$ in cultured

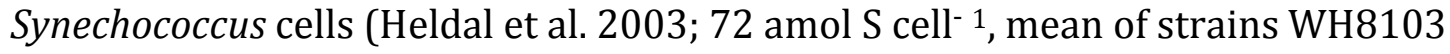
and WH7803). Even with the caveats about P and $S$ that are explored below, GLMestimated least square geometric mean ratios of Si:S and Si:P for individual stations and depths in Table 2 are similar to those previously reported in Synechococcus cells collected from the eastern tropical North Pacific and the Sargasso Sea (Baines et al., 2012).

Ideally, both of the essential elements $\mathrm{P}$ and $\mathrm{S}$ can be used for biomass normalization, i.e. to compensate for any natural community variations in cell size. Biomass normalization for such a highly adaptable and cosmopolitan organism as Synechococcus must be considered carefully, however. Even essential elemental behaviors may be affected by independent physiological processes, some of which may be strain-dependent (as previously suggested for $\mathrm{Si}$ ). Despite the environmental context provided by our field data, the physiological processes driving elemental accumulation in Synechococcus do remain rather unconstrained.

In a previous study of Synechococcus field assemblages that measured P and S quotas, Twining et al. (2010) found that $P$ content was relatively invariant with depth, even across mesoscale eddy features that perturbed other elemental quotas. This result is replicated here for $\mathrm{P}$, which was not significantly variant across SML and DCM depths [Table 3; Fig 2.]. We observed elevated S quotas in SML cells, also previously reported, which has been posited to reflect elevated protein content and/or glutathione reductant concentrations (both providing S-enrichment) in oxidatively-stressed cells from the upper euphotic zone (Dupont et al., 2004; Twining et al., 2010). In the P-stressed, if not P-limiting, North Atlantic surface waters of this study (Lomas et al., 2014; Mather et al., 2008), substitution of S for P in phospholipids may also contribute to higher S quotas in the SML (Van Mooy et al., 2009). Substitution of this type may be especially noticeable in picocyanobacteria with high surface area-to-volume (cell membrane-to-biomass) ratios in a region where comparatively scarce $\mathrm{P}$ is highly economized. 
414 Quotas of S were higher in the SML than at the DCM, similar to trends in Si quotas.

415 Despite station and cruise also being significant effects for S quotas [Table 3], Si:S

416 ratios were insensitive to all effects (range: $0.4-3.8 \mathrm{~mol}: \mathrm{mol}$ ) [Table 2]. Our data

417 cannot provide a clear physiological mechanism to link Si accumulation and S-

418 indicated biomass, but do suggest that SML cells with higher Si and S contents may

419 be larger and/or S-rich, while DCM cells with lower Si and S contents may be smaller

420 and/or S-poor. The cause for any such relationship between Si and Synechococcus

421

422

423

424

425

426

427

428

429

430

431

432

433

434

435

436

437

438

439

440

441

442

443

444

445

446

447

448

449

450

451

452

453

454

455

456

457 cell biomass, as indicated by invariant $\mathrm{Si}$ S ratios, may ultimately be related to presently unquantified parameters such as clade-specific physiology and the underlying mechanisms of cellular Si acquisition and retention.

Quotas of P show no influence of a depth effect but do show a relationship with cruise (lower P quotas during the July/BATS283 cruise) which, in addition to any unquantified clade-specific physiological effects, may reflect changes in $\mathrm{P}$ availability and/or utilization at different times of year. Dissolved macronutrient concentrations measured by the BATS program are, however, typically below detection in the upper water column due to the ultra-oligotrophic conditions throughout the sampling periods. Unlike ratios of Si:S, ratios of Si:P show significant effects for cruise and depth, with SML cells possessing elevated Si:P [Table 2], further indicating additional accumulation of Si in the SML relative to P-indicated biomass. An important caveat is that approximately $25 \%$ of P measurements were below detection by SXRF, especially during the mid-summer BATS283 cruise (14 of 52 cells were below detection for $\mathrm{P}$ ), potentially cautioning the universal usage of $\mathrm{P}$ as a biomass normalizer despite its relative invariance across SML and DCM ecosystems.

\section{Contributions of Synechococcus Si to the bSi pool}

We calculated potential contributions of Synechococcus Si to the $0.4-3 \mu \mathrm{m}$ (small) bSi pool at each station and depth [Table 2, rightmost column] by multiplying the depth-specific (SML or DCM) distribution of cellular Si quotas [Fig 2] by the local Synechococcus cell abundances, then normalizing to locally measured small bSi. Estimates ranged over 30 -fold, from 2 to $63 \%$ of the small bSi pool, though these contributions were always $\leq 8 \%$ of total bSi. Greater potential contributions to small $\mathrm{bSi}$ that were observed during the autumn cruises reflected the lower bSi concentrations during the autumn bSi minimum. Lesser contributions were associated with the BATS283 cruise during which the station was occupied by a mesoscale eddy which resulted in enhanced diatom biomass [Table 2]. While most $\mathrm{bSi}$ is present in the larger size fraction, it appears there is demonstrable, albeit highly variable, potential for Synechococcus Si accumulation to contribute to the small bSi size-fraction. Consideration of additional processes such as aggregation and cycling of detrital material, diatom quotas, and grazing will be required to constrain the effects of Synechococcus on the total bSi cycle of these ecosystems.

Potential causes for Si variability in Synechococcus 
458 What is driving the wide variability in Si quotas? Culture work has demonstrated

459 that Synechococcus lacks an absolute Si requirement: strains show no growth

460 reduction at zero-added Si $(\approx 1 \mu \mathrm{M}$ ambient Si in Sargasso seawater culturing

461 media) and no growth enhancement at higher Si concentrations (Brzezinski et al., 2016). Nevertheless, natural cells analyzed by SXRF have nearly all accumulated Si to the amol cell ${ }^{-1}$ level even in the low ambient silicic acid concentrations of the Sargasso Sea, with some cells accumulating many thousands of amol. For spherical cells with an approximate diameter of 1 micron, even 1 amol of Si accumulation is equivalent to $\approx 2 \mathrm{mM}$ (i.e. $\mathrm{Si}(\mathrm{OH})_{4}$ saturation in seawater) intracellular $\mathrm{Si}$, indicating $\mathrm{Si}$ accumulation against a strong concentration gradient (ambient dissolved silicic acid: $0.6-1.3 \mu \mathrm{M}$ ). This counter-concentration gradient argument-which would also apply to diatoms with their tens to hundreds of $\mathrm{mM}$ of intracellular Si, e.g. (Martin Jézéquel et al., 2000)-presumes that Si is kept in solution as silicic acid, which is not yet clear for Synechococcus. Accumulation may be enhanced by conversion to insoluble particulate forms, either biologically mediated or abiotically, the density effects of which are examined later.

Several possibilities for Si accumulation can be considered via comparison to other elemental behaviors. The biologically essential element $P$ exhibits a much narrower range in cell quotas than Si [Fig. 2], with S quotas ranging somewhat intermediate to $\mathrm{Si}$ and P. For all three elements, population variability is attributed mostly to cells with higher quotas, as low-end quotas are on the order of $1-10 \mathrm{amol} \mathrm{cell}^{-1}$ for all three elements. In other words, most quota distributions have a notable positive skew even after logarithmic transformation. The phenomenon of high-quota cells driving population heterogeneity has been shown previously in a diatom growth model for P utilization when modeled under conditions of non-limiting nutrient availability (Fredrick et al., 2013). Such results are consistent with Si's putatively non-essential nature in Synechococcus and also the general availability (non-limiting nature) of $S$ in the marine environment.

Major drivers of heterogeneity implicated in the Fredrick et al. diatom growth model were: physiological maximum nutrient content per cell (i.e. storage capacity, or size); and how nutrients are partitioned to daughter cells during cell division (heterogeneity in growth dilution). Populations can also show heterogeneity in cell quotas due to variability in dissolved nutrient fields, an effect whose scale (factor of two variability in dissolved silicic acid) is dwarfed by the scale in Si quota variability (four orders of magnitude) [Table 2]. In the absence of strong heterogeneity in ambient silicic acid concentrations, unassessed nutrient concentrations in microenvironments on the scale of the cell (e.g. proximity to Si-rich diatoms or marine snow aggregates with hundreds of micromolar dissolved Si (Brzezinski et al., 1997)) may nevertheless affect the availability of elements to individual organisms. Other sources of quota heterogeneity may include different elemental requirements or accumulation tendencies by different ecotypes/clades [e.g. Fig. 4], and two possibilities not discernable in our dataset: variations in quotas throughout the cell cycle; or uptake in response to specific stressors. Given the apparent non-essential nature of $\mathrm{Si}$, at least in the six cultured Synechococcus strains examined by 
504 Brzezinski et al. (2016) and the element's as-yet-unclear uptake and storage

505 mechanics, all possibilities remain potential explanations for the wide quota ranges

506 for Si observed in natural Synechococcus.

507

508

509

Intracellular versus extracellular $\mathrm{Si}$

510

511 A study by Tang et al. (2014) recently demonstrated Si accumulation within the extracellular polymeric substances (EPS) associated with decomposing

512

513

514

515

516

517

518

519

520

521

522

523

524

525

526

527

528

529

530

531

532

533

534

535

536

537

538

539

540

541

542

543

544

545

546

547

548 Synechococcus cultures and in natural amorphous "micro-bleb" particles collected near Bermuda. Their results implicated abiotic or microbially mediated decomposition that drives Si localization to EPS during the aging and vertical export of Synechococcus-associated Si. Our observations on fresh cells, by comparison, demonstrate consistent Si accumulation by intact Synechococcus cells before decomposition. The spatial resolution of the SXRF cellular mapping methodology used here, though quantitative across the entire cell, is nevertheless insufficient to demonstrate where $\mathrm{Si}$ is physically located (i.e. intracellular versus extracellular). Improvements in quantitative, nanometer-scale SXRF mapping may soon allow quantitative extracellular/intracellular discernment on such small organisms (Deng et al., 2015a). The particulate speciation of Si in Synechococcus cultures examined via alternative $\mathrm{x}$-ray methods is also the focus of a forthcoming manuscript by our group.

\section{Effects of Si on cell density}

To calculate maximum potential effects of Si accumulation on cell density, we can assume that all $\mathrm{Si}$ is present as amorphous opal (formula $\mathrm{SiO}_{2} \cdot 1.5 \mathrm{H}_{2} \mathrm{O}, 87.1 \mathrm{~g} \mathrm{~mol}^{-1}$, density $2.1 \mathrm{~g} \mathrm{~cm}^{-3}$ ). In an "average" cell, all $47 \mathrm{amol} \mathrm{Si} \mathrm{would} \mathrm{equate} \mathrm{to} 4.1 \mathrm{fg}$ opal with a volume of $2.0 \mathrm{aL}$. The combined, silicified excess cell density is less than $1 \%$ greater than the unsilicified cell, with opaline Si representing $\approx 0.8 \%$ of the average silicified cell's mass. For an upper-quartile cell with 1000 amol opaline Si, the effect on cell excess density increases: $14 \%$ of the cell mass as $\mathrm{Si}$, with a silicified cell density $\approx 7 \%$ greater than an unsilicified cell. While the excess density imparted by putatively opaline Si mass is non-negligible, neither "average" nor highly silicified cells would be expected to have sinking rates estimated using Stokes' law of $>2 \mathrm{~mm}$ $\mathrm{d}^{-1}$ [Table 4]. While it thus appears unlikely that silicification affects the sinking rates of individual Synechococcus cells, significantly greater sinking rates would be expected for larger aggregates or fecal pellets. Larger aggregates that have accumulated similar levels of excess density, either via silicified cells or through their own accumulation Si from seawater (Tang et al., 2014) would settle much more rapidly.

\section{Conclusions}

It remains surprising that Synechococcus, which has no known physiological use for Si and lacks a clear Si requirement in cultured strains, nevertheless accumulates this element to intracellular concentrations comparable to, and often exceeding, biologically essential P and S. Our data show that Si accumulation is a common

549 feature of Synechococcus communities in oligotrophic regions. Cellular quotas of $\mathrm{Si}$ were similar, but highly variable, across several stations in the North Atlantic 
occupied at different times of year and in different years. Si quotas showed no consistent relationship with ambient bSi concentrations or Synechococcus abundances but may contribute significantly to the small $(<3 \mu \mathrm{m})$ bSi pool. Even within the low and narrow silicic acid concentrations of the euphotic oligotrophic gyre, Si content in cells from the SML was nearly double that of cells from the DCM. In the low $\mathrm{Si}$ concentrations of the oligotrophic gyres, parameters other than bulk $\mathrm{Si}$ availability-such as shifts in Synechococcus community structure-may exert control over highly variable cellular Si contents. While the potential presence of solid silica phases in individual cells is unlikely to provide enough excess density to impart significant vertical settling speeds on single living cells, Si accumulation may influence settling speeds in larger aggregates composed of such cells.

564

\section{Acknowledgments}

We thank the BATS program for cruise access and E. Lachenmyer, I. Marquez, C. Griffin for shipboard assistance. This project was funded by the National Science Foundation to BST (OCE 1131046), JWK and MAB (OCE 1335012) and SBB and JLC (OCE 1131139). This research used resources of the Advanced Photon Source, a U.S. Department of Energy (DOE) Office of Science User Facility operated for the DOE Office of Science by Argonne National Laboratory under Contract No. DE-AC02$06 \mathrm{CH} 11357$.

\section{Figure and Table Captions}

Table 1: Synchrotron analytical run metadata: run number, analyzed cruise, and typical cell region of interest (ROI) elemental uncertainties for Si, P and S (median \pm 1 s.d., in percent). Elemental background levels vary across samples, runs, and even within sample grids, so in lieu of detection limits, typical (median) cell-tobackground ROI ratios are provided. Additional methodological information is provided in the text.

Table 2: SXRF-measured single-cell Si quotas and biomass ratios along with key environmental parameters measured from the same bottles. SML: surface mixed layer (5 - $10 \mathrm{~m}$ sampling depth). DCM: deep chlorophyll maximum (75 - $88 \mathrm{~m}$ sampling depth). BATS site located at $31^{\circ} 40^{\prime} \mathrm{N} / 64^{\circ} 10^{\prime} \mathrm{W}$. Asterisks $\left({ }^{*}\right)$ : Least-square means and std. errors from the GLM described in the text. Bold: cast instead of station number. Italics (BATS-286, Cast 1, DCM): informational SXRF values only due to the few number of samples analyzed.

Table 3: Within a generalized linear model containing the specified effects (cruise, station nested within cruise, and depth), the degrees of freedom (DF) and significance of the effects ( $p$-values) on elemental quotas ( $\log _{10}$ element/cell) and quota ratios. Bold values: effects significant at the $\mathrm{p}<0.05$ level.

Table 4: Maximum sinking speeds estimated via Stokes' Law for spherical particles of various diameters that have accumulated amorphous opal $\mathrm{Si}$, and thus excess density, at mean (47 amol Si cell $\left.{ }^{-1}\right)$ and upper-quartile (1000 amol Si cell- $\left.{ }^{-1}\right)$ levels. Settling speeds of individual silicified Synechococcus cells (1 $\mu \mathrm{m}$ diameter) are $\leq 2$ 
$596 \mathrm{~mm} \mathrm{~d}^{-1}$, but larger aggregates of similar excess density could settle much more

597 rapidly.

598

599

Figure 1: Locations of major sampling stations in the western Atlantic.

600

601 Figure 2: Histograms of Synechococcus Si, P, and S quotas in amol cell- ${ }^{1}$ (note

602 matched log y-axis scales). Data are from all cruises and stations, binned by depth:

603 left, surface mixed layer (SML; n=73); right, deep chlorophyll maximum (DCM;

$604 \mathrm{n}=41$ ). Asterisks: LSQ-geometric-means indicated by dashed lines are significantly

605 different between SML and DCM for Si and S, but not for P.

606

607

Figure 3: Relationships between LSQ-geometric-mean SXRF cellular Si quotas (y-

608

axes) and various environmental parameters (x-axes) were not significant (best fit

609

610

611

612

613 lines, Pearson $r$ and p-values; $\mathrm{n}=11$ ). Blue points: SML. Green points: DCM.

614

615

616

617

618

619

620

Figure 4: Synechococcus operational taxonomic unit (OTU) contributions by various identified/cultured clades (Mazard et al., 2012) and two unnamed clusters (U1 and U2) to communities from the surface mixed layer (SML; 5 - $10 \mathrm{~m}$ sampling depth) and deep chlorophyll maximum (DCM; 75 - 88 m sampling depth).

\section{References}

Altschul, S. F., Gish, W., Miller, W., Myers, E. W. and Lipman, D. J.: Basic local alignment search tool, Journal of Molecular Biology, 215(3), 403-410, doi:10.1016/S0022-2836(05)80360-2, 1990.

621 Baines, S. B., Twining, B. S., Brzezinski, M. A., Krause, J. W., Vogt, S., Assael, D. and 622 McDaniel, H.: Significant silicon accumulation by marine picocyanobacteria, Nature 623 Geoscience, 5(12), 886-891, doi:10.1038/ngeo1641, 2012.

624 Bertilsson, S., Berglund, O. and Karl, D. M.: Elemental composition of marine 625 Prochlorococcus and Synechococcus: Implications for the ecological stoichiometry 626 of the sea, Limnology and Oceanography, 2003.

627 Brzezinski, M. A. and Nelson, D. M.: The annual silica cycle in the Sargasso Sea near 628 Bermuda, Deep Sea Research Part I: Oceanographic Research Papers, 42(7), 1215629 1237, doi:10.1016/0967-0637(95)93592-3, 1995.

630 Brzezinski, M. A., Alldredge, A. L. and O'Bryan, L. M.: Silica cycling within marine 631 snow, Limnology and Oceanography, 42(8), 1706-1713, 632 doi:10.4319/lo.1997.42.8.1706, 1997.

633 Brzezinski, M. A., Krause, J. W., Baines, S. B., Collier, J. L., Ohnemus, D. C. and Twining, 634 B. S.: Patterns and Regulation of Silicon Accumulation in Synechococcus spp., 635 Limnology and Oceanography (in review). 2016. 
636 Caporaso, J. G., Kuczynski, J., Stombaugh, J., Bittinger, K., Bushman, F. D., Costello, E.

637 K., Fierer, N., Peña, A. G., Goodrich, J. K., Gordon, J. I., Huttley, G. A., Kelley, S. T.,

638 Knights, D., Koenig, J. E., Ley, R. E., Lozupone, C. A., McDonald, D., Muegge, B. D.,

639 Pirrung, M., Reeder, J., Sevinsky, J. R., Turnbaugh, P. J., Walters, W. A., Widmann, J.,

640 Yatsunenko, T., Zaneveld, J. and Knight, R.: QIIME allows analysis of high-throughput

641 community sequencing data, Nat Meth, 7(5), 335-336, doi:10.1038/nmeth.f.303,

6422010.

643 Collier, J. L. and Palenik, B.: Phycoerythrin-containing picoplankton in the Southern

644 California Bight, Deep Sea Research Part II: Topical Studies in Oceanography, 2003.

645 Deng, J., Vine, D. J., Chen, S., Nashed, Y. S. G., Jin, Q., Phillips, N. W., Peterka, T., Ross, R., 646 Vogt, S. and Jacobsen, C. J.: Simultaneous cryo X-ray ptychographic and fluorescence 647 microscopy of green algae, Proceedings of the National Academy of Sciences, 112(8), 648 2314-2319, doi:10.1073/pnas.1413003112, 2015a.

649 Deng, W., Monks, L. and Neuer, S.: Effects of clay minerals on the aggregation and 650 subsequent settling of marine Synechococcus, Limnology and Oceanography, 60(3), 651 805-816, doi:10.1002/lno.10059, 2015b.

652 Dupont, C. L., Goepfert, T. J., Lo, P. and Wei, L.: Diurnal cycling of glutathione in 653 marine phytoplankton: Field and culture studies, Limnology and Oceanography, 6542004.

655 Edgar, R. C.: Search and clustering orders of magnitude faster than BLAST, 656 Bioinformatics, 26(19), 2460-2461, doi:10.1093/bioinformatics/btq461, 2010.

657 Fredrick, N. D., Berges, J. A., Twining, B. S., Nuñez-Milland, D. and Hellweger, F. L.:

658 Use of Agent-Based Modeling To Explore the Mechanisms of Intracellular

659 Phosphorus Heterogeneity in Cultured Phytoplankton, Applied and Environmental 660 Microbiology, 79(14), 4359-4368, doi:10.1128/AEM.00487-13, 2013.

661 Goericke, R.: Response of phytoplankton community structure and taxon-specific 662 growth rates to seasonally varying physical forcing in the Sargasso Sea off Bermuda, 663 Limnology and Oceanography, 43(5), 921-935 [online] Available from:

664 http://onlinelibrary.wiley.com/doi/10.4319/lo.1998.43.5.0921/full, 1998.

665 Guidi, L., Chaffron, S., Bittner, L., Eveillard, D. and Larhlimi, A.: Plankton networks 666 driving carbon export in the oligotrophic ocean, Nature, doi:10.1038/nature16942, 6672016.

668 Haas, B. J., Gevers, D., Earl, A. M., Feldgarden, M., Ward, D. V., Giannoukos, G., Ciulla, 669 D., Tabbaa, D., Highlander, S. K., Sodergren, E., Methe, B., DeSantis, T. Z., The Human 670 Microbiome Consortium, Petrosino, J. F., Knight, R. and Birren, B. W.: Chimeric 16S 671 rRNA sequence formation and detection in Sanger and 454-pyrosequenced PCR 672 amplicons, Genome Research, 21(3), 494-504, doi:10.1101/gr.112730.110, 2011. 
673 Hall, T. A.: BioEdit: a user-friendly biological sequence alignment editor and analysis

674 program for Windows 95/98/NT, Nucleic acids symposium series, 1999.

675 Heldal, M., Scanlan, D. J., Norland, S., Thingstad, F. and Mann, N. H.: Elemental

676 composition of single cells of various strains of marine Prochlorococcus and

677 Synechococcus using X-ray microanalysis, Limnology and Oceanography, 48(5),

678 1732-1743, 2003.

679 Krause, J. W., Brzezinski, M. A. and Landry, M. R.: The effects of biogenic silica 680 detritus, zooplankton grazing, and diatom size structure on silicon cycling in the

681 euphotic zone of the eastern equatorial Pacific, Limnology and Oceanography, 2010.

682 Krause, J. W., Lomas, M. W. and Nelson, D. M.: Biogenic silica at the Bermuda Atlantic 683 Time-series Study site in the Sargasso Sea: Temporal changes and their inferred 684 controls based on a 15-year record, Global Biogeochem. Cycles, 23(3),

685 doi:10.1029/2008GB003236, 2009.

686 Liu, H., Campbell, L. and Landry, M. R.: Growth and mortality rates of

687 Prochlorococcus and Synechococcus measured with a selective inhibitor technique,

688 Marine Ecology Progress Series, 1995.

689 Lomas, M. W., Bonachela, J. A., Levin, S. A. and Martiny, A. C.: Impact of ocean

690 phytoplankton diversity on phosphate uptake, Proceedings of the National Academy

691 of Sciences, 111(49), 17540-17545, doi:10.1073/pnas.1420760111, 2014.

692 Lomas, M. W., Steinberg, D. K., Dickey, T., Carlson, C. A., Nelson, N. B., Condon, R. H.

693 and Bates, N. R.: Increased ocean carbon export in the Sargasso Sea linked to climate

694 variability is countered by its enhanced mesopelagic attenuation, Biogeosciences,

695 7(1), 57-70, doi:10.5194/bg-7-57-2010, 2010.

696 Marquez, I. A.: The consequences of mesoscale eddies on diatom production and the 697 coupling of Si and organic matter export in the Sargasso Sea, University of South 698 Alabama. 2015.

699 Martin Jézéquel, V., Hildebrand, M. and Brzezinski, M. A.: Silicon metabolism in

700 diatoms: implications for growth, Journal of Phycology, 36(5), 821-840, 2000.

701 Mather, R. L., Reynolds, S. E., Wolff, G. A. and Williams, R. G.: Phosphorus cycling in

702 the North and South Atlantic Ocean subtropical gyres, Nature Geoscience,

703 doi:10.1038/ngeo232, 2008.

704 Mazard, S., Ostrowski, M., Partensky, F. and Scanlan, D. J.: Multi-locus sequence

705 analysis, taxonomic resolution and biogeography of marine Synechococcus,

706 Environmental Microbiology, 14(2), 372-386, doi:10.1111/j.1462-

$707 \quad 2920.2011 .02514 . x, 2012$.

708 Núñez-Milland, D. R., Baines, S. B., Vogt, S. and Twining, B. S.: Quantification of 
phosphorus in single cells using synchrotron X-ray fluorescence, Journal of Synchrotron Radiation, 17(4), 560-566, doi:10.1107/S0909049510014020, 2010.

711 Polovina, J. J., Howell, E. A. and Abecassis, M.: Ocean\&apos;s least productive waters 712 are expanding, Geophysical Research Letters, 35(3), doi:10.1029/2007GL031745, 7132008.

714 Saito, M. A., Rocap, G. and Moffett, J. W.: Production of cobalt binding ligands in a 715 Synechococcus feature at the Costa Rica upwelling dome, Limnology and

716 Oceanography, 50(1), 279-290, doi:10.4319/lo.2005.50.1.0279, 2005.

717 Scanlan, D. J., Ostrowski, M., Mazard, S., Dufresne, A., Garczarek, L., Hess, W. R., Post, 718 A. F., Hagemann, M., Paulsen, I. and Partensky, F.: Ecological Genomics of Marine 719 Picocyanobacteria, Microbiology and Molecular Biology Reviews, 73(2), 249-299, 720 doi:10.1128/MMBR.00035-08, 2009.

721 Stukel, M. R., Décima, M., Selph, K. E., Taniguchi, D. A. A. and Landry, M. R.: The role of Synechococcus in vertical flux in the Costa Rica upwelling dome, Progress in Oceanography, 112-113, 49-59, doi:10.1016/j.pocean.2013.04.003, 2013. Tamura, K., Stecher, G., Peterson, D., Filipski, A. and Kumar, S.: MEGA6: Molecular Evolutionary Genetics Analysis Version 6.0, Mol Biol Evol, 30(12), 2725-2729, doi:10.1093/molbev/mst197, 2013.

727 Tang, T., Kisslinger, K. and Lee, C.: Silicate deposition during decomposition of 728 cyanobacteria may promote export of picophytoplankton to the deep ocean, Nature 729 Communications, 5, doi:10.1038/ncomms5143, 2014.

730 Twining, B. S., Baines, S. B., Bozard, J. B., Vogt, S., Walker, E. A. and Nelson, D. M.: 731 Metal quotas of plankton in the equatorial Pacific Ocean, Deep Sea Research Part II: 732 Topical Studies in Oceanography, 58(3-4), 325-341,

733 doi:10.1016/j.dsr2.2010.08.018, 2011.

734 Twining, B. S., Baines, S. B., Fisher, N. S., Maser, J., Vogt, S., Jacobsen, C., Tovar735 Sánchez, A. and Sañudo-Wilhelmy, S. A.: Quantifying Trace Elements in Individual 736 Aquatic Protist Cells with a Synchrotron X-ray Fluorescence Microprobe, Analytical 737 Chemistry, 75(15), 3806-3816, doi:10.1021/ac034227z, 2003.

738 Twining, B. S., Nunez-Milland, D. and Vogt, S.: Variations in Synechococcus cell 739 quotas of phosphorus, sulfur, manganese, iron, nickel, and zinc within mesoscale 740 eddies in the Sargasso Sea, Limnology and Oceanography, 2010.

741 Van Mooy, B., Fredricks, H. F., Pedler, B. E. and Dyhrman, S. T.: Phytoplankton in the 742 ocean use non-phosphorus lipids in response to phosphorus scarcity, Nature, 2009.

743 Vogt, S.: MAPS : A set of software tools for analysis and visualization of 3D X-ray 744 fluorescence data sets, J. Phys. IV France, 104, 635-638, doi:10.1051/jp4:20030160, 
7452003.

746 Wang, W. and Dei, R.: Bioavailability of iron complexed with organic colloids to the 747 cyanobacteria Synechococcus and Trichodesmium, Aquatic Microbial Ecology, 748 33(3), 247-259, 2003.

749 


\begin{tabular}{cccccccc} 
& & \multicolumn{2}{c}{ Median Cell ROI Uncertainty } & \multicolumn{3}{c}{ Median Cell/Bkgr ROI } \\
& & \multicolumn{2}{c}{ [percent \pm 1 s.d.] } & \multicolumn{2}{c}{ Ratio [percent] } \\
Analytical Run & Cruise & $\mathrm{Si}$ & $\mathrm{P}$ & $\mathrm{S}$ & $\mathrm{Si}$ & $\mathrm{P}$ & $\mathrm{S}$ \\
\hline $2012-3$ & BATS283 & $4.7 \pm 3.4$ & $14 \pm 14$ & $2.6 \pm 1.6$ & 152 & 874 & 412 \\
$2013-1$ & BATS286 & $3.2 \pm 3.3$ & $10 \pm 18$ & $3.2 \pm 2.6$ & 127 & 404 & 424 \\
$2013-3$ & BVAL & $8.1 \pm 6.8$ & $17 \pm 11$ & $5.4 \pm 2.6$ & 165 & 614 & 345
\end{tabular}

Table 1: Synchrotron analytical run metadata: run number, analyzed cruise, and typical cell region of interest (ROI) elemental uncertainties for Si, $\mathrm{P}$ and $\mathrm{S}$ (median \pm 1 s.d., in percent). Elemental background levels vary across samples, runs, and even within sample grids, so in lieu of detection limits, typical (median) cell-to-background ROI ratios are provided. Additional methodological information is provided in the text. 


\begin{tabular}{|c|c|c|c|c|c|c|c|c|c|c|c|c|c|c|}
\hline Cruise & $\begin{array}{l}\text { Cast/ } \\
\text { Stn }\end{array}$ & Depth & Location & Date & $\begin{array}{c}\text { Ambient } \\
\mathrm{SiOH}_{4} \\
(\mu \mathrm{M})\end{array}$ & $\begin{array}{c}\text { N Cells } \\
\text { SXRF }\end{array}$ & $\begin{array}{c}\mathrm{Si} \\
\text { (amol/cell) } \\
\text { SXRF* }\end{array}$ & $\begin{array}{c}\text { Si:P } \\
\text { (mol:mol) } \\
\text { SXRF* }\end{array}$ & $\begin{array}{c}\text { Si:S } \\
\text { (mol:mol) } \\
\text { SXRF* }\end{array}$ & $\begin{array}{c}0.4-3 \mu \mathrm{m} \\
\text { small bSi } \\
\left(\mathrm{nmol} \mathrm{L}^{-1}\right)\end{array}$ & $\begin{array}{c}>3 \mu \mathrm{m} \\
\text { large bSi } \\
\left(\mathrm{nmol} \mathrm{L}^{-1}\right)\end{array}$ & $\begin{array}{c}\% b S i \\
\text { small }\end{array}$ & $\begin{array}{c}\text { Syn. } \\
\text { cells/mL }\end{array}$ & $\begin{array}{c}\text { Small bSi } \\
\text { potentially } \\
\text { Syn. }\end{array}$ \\
\hline \multirow[t]{4}{*}{ BATS-283 } & 1 & SML & BATS & 11-Jul-2012 & 0.8 & 12 & $57 \pm 2$ & $3.8 \pm 0.2$ & $1.3 \pm 0.2$ & 39 & 139 & $22 \%$ & 12,146 & $3 \%$ \\
\hline & & DCM & & & 1.3 & 16 & $16 \pm 1$ & $0.6 \pm 0.2$ & $0.3 \pm 0.2$ & 11 & 140 & $7 \%$ & 2,210 & $2 \%$ \\
\hline & 3 & SML & & 12-Jul-2012 & 0.9 & 15 & $64 \pm 1$ & $3.7 \pm 0.2$ & $0.3 \pm 0.2$ & 14 & 203 & $6 \%$ & 14,759 & $12 \%$ \\
\hline & & DCM & & & 0.9 & 9 & $14 \pm 1$ & $1.1 \pm 0.2$ & $0.8 \pm 0.2$ & 8.8 & 143 & $6 \%$ & 13,352 & $12 \%$ \\
\hline \multirow[t]{3}{*}{ BATS-286 } & 1 & SML & BATS & 18-Oct-2012 & 0.8 & 10 & $42 \pm 1$ & $2.5 \pm 0.2$ & $0.9 \pm 0.2$ & 4.9 & 12 & $29 \%$ & 12,638 & $29 \%$ \\
\hline & & DCM & & & 0.6 & 2 & $37 \pm 2$ & $2.7 \pm 0.3$ & $3.2 \pm 0.4$ & 1.3 & 11 & $10 \%$ & 1,775 & $11 \%$ \\
\hline & 3 & DCM & & $19-O c t-2012$ & 0.6 & 5 & $60 \pm 2$ & $1.6 \pm 0.2$ & $2.4 \pm 0.3$ & 2.3 & 12 & $16 \%$ & 8,709 & $31 \%$ \\
\hline \multirow[t]{5}{*}{ BVAL } & 2 & SML & BATS & 30-Sep-2013 & 1.2 & 7 & $40 \pm 2$ & $1.7 \pm 0.2$ & $0.6 \pm 0.2$ & 2.1 & 13 & $14 \%$ & 3,949 & $21 \%$ \\
\hline & & DCM & & & 1.0 & 10 & $32 \pm 2$ & $0.4 \pm 0.2$ & $1.8 \pm 0.3$ & 1.7 & 13 & $12 \%$ & 1,618 & $8 \%$ \\
\hline & 5 & SML & $28^{\circ} 39.8^{\prime} \mathrm{N} / 64^{\circ} 36.7^{\prime} \mathrm{W}$ & 1-Oct-2013 & 0.9 & 9 & $38 \pm 2$ & $0.5 \pm 0.2$ & $0.6 \pm 0.2$ & 1.3 & 9.8 & $12 \%$ & 4,008 & $34 \%$ \\
\hline & 10 & SML & $23^{\circ} 10.1^{\prime} \mathrm{N} / 65^{\circ} 21.9^{\prime} \mathrm{W}$ & 3-Oct-2013 & 1.3 & 11 & $55 \pm 2$ & $2.3 \pm 0.2$ & $0.8 \pm 0.2$ & 1.7 & 15 & $10 \%$ & 5,500 & $37 \%$ \\
\hline & 12 & SML & $21^{\circ} 40.2^{\prime} \mathrm{N} / 65^{\circ} 40.0^{\prime} \mathrm{W}$ & 4-Oct-2013 & 1.3 & 11 & $59 \pm 2$ & $2.8 \pm 0.3$ & $0.7 \pm 0.2$ & 1.4 & 13 & $10 \%$ & 7,952 & $63 \%$ \\
\hline
\end{tabular}

Table 2: SXRF-measured single-cell Si quotas and biomass ratios along with key environmental parameters measured from the same bottles. SML: surface mixed layer (5 - $10 \mathrm{~m}$ sampling depth). DCM: deep chlorophyll maximum (75 - 88 $\mathrm{m}$ sampling depth). BATS site located at $31^{\circ} 40^{\prime} \mathrm{N} / 64^{\circ} 10^{\prime} \mathrm{W}$. Asterisks $\left({ }^{*}\right)$ : Least-square means and std. errors from the GLM described in the text. Bold: cast instead of station number. Italics (BATS-286, Cast 1, DCM): informational SXRF values only due to the few number of samples analyzed. 


\begin{tabular}{l|c|cccccc} 
Effect & DF & $\log \mathrm{Si} /$ cell & $\log \mathrm{P} /$ cell & $\log \mathrm{S} /$ cell & $\log \mathrm{Si}: \mathrm{P}$ & $\log \mathrm{Si}: \mathrm{S}$ & $\log \mathrm{P}: \mathrm{S}$ \\
\hline Cruise & 2 & 0.723 & $\mathbf{0 . 0 0 8}$ & $\mathbf{0 . 0 0 2}$ & $\mathbf{0 . 0 2 9}$ & 0.051 & $<.0001$ \\
Station [Cruise] & 5 & 0.840 & 0.067 & $\mathbf{0 . 0 3 7}$ & 0.089 & 0.301 & $\mathbf{0 . 0 0 4}$ \\
Depth & 1 & $\mathbf{0 . 0 2 9}$ & 0.288 & $<.0001$ & $\mathbf{. 0 0 0 1}$ & 0.422 & $<.0001$
\end{tabular}

Table 3: Within a generalized linear model (GLM) containing the specified effects (cruise, station nested within cruise, and depth), the degrees of freedom (DF) and significance of the effects ( $p$-values) on elemental quotas ( $\log _{10}$ element/cell) and quota ratios. Bold values: effects significant at the $p<0.05$ level. 


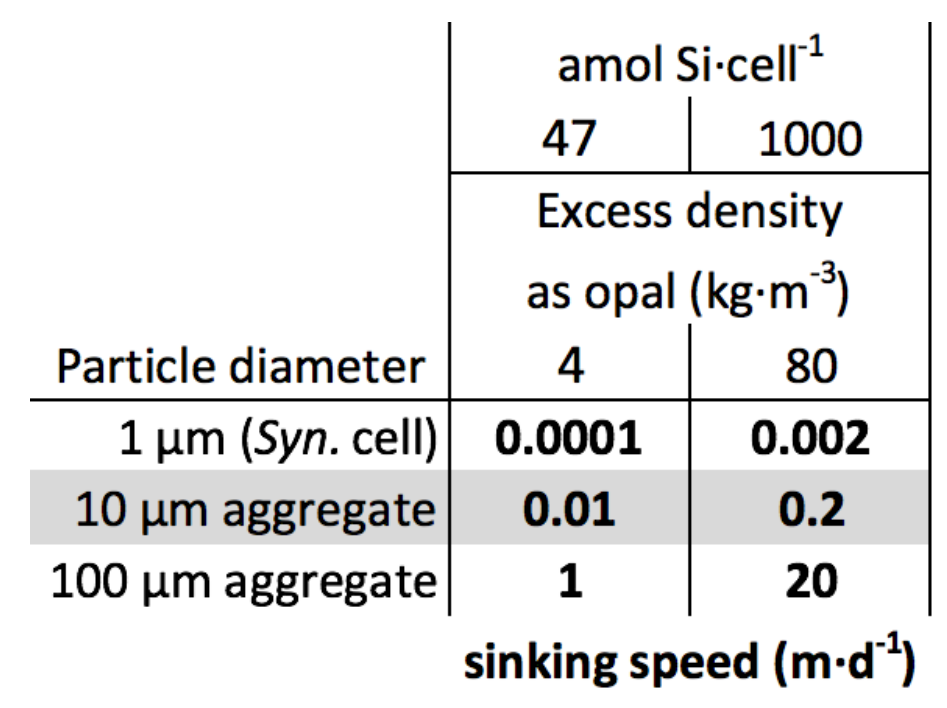

Table 4: Maximum sinking speeds estimated via Stokes' Law for spherical particles of various diameters that have accumulated amorphous opal $\mathrm{Si}$, and thus excess density, at mean (47 amol Si cell-1) and upper-quartile (1000 amol Si cell-1) levels. Settling speeds of individual silicified Synechococcus cells ( $\approx 1 \mu \mathrm{m}$ diameter) are $\leq 2 \mathrm{~mm} \mathrm{~d}^{-1}$, but larger aggregates of similar excess density could settle much more rapidly. 


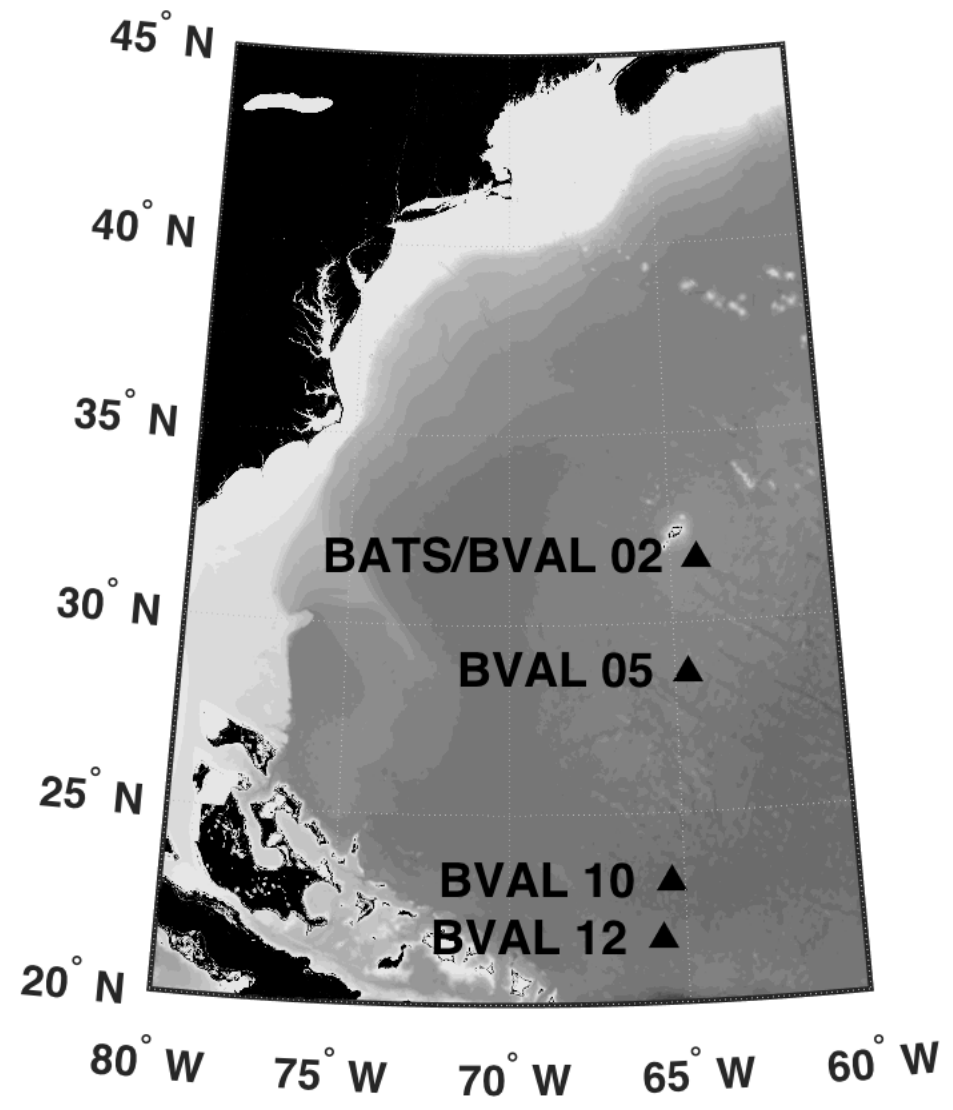

Figure 1: Locations of major sampling stations described in the text. 


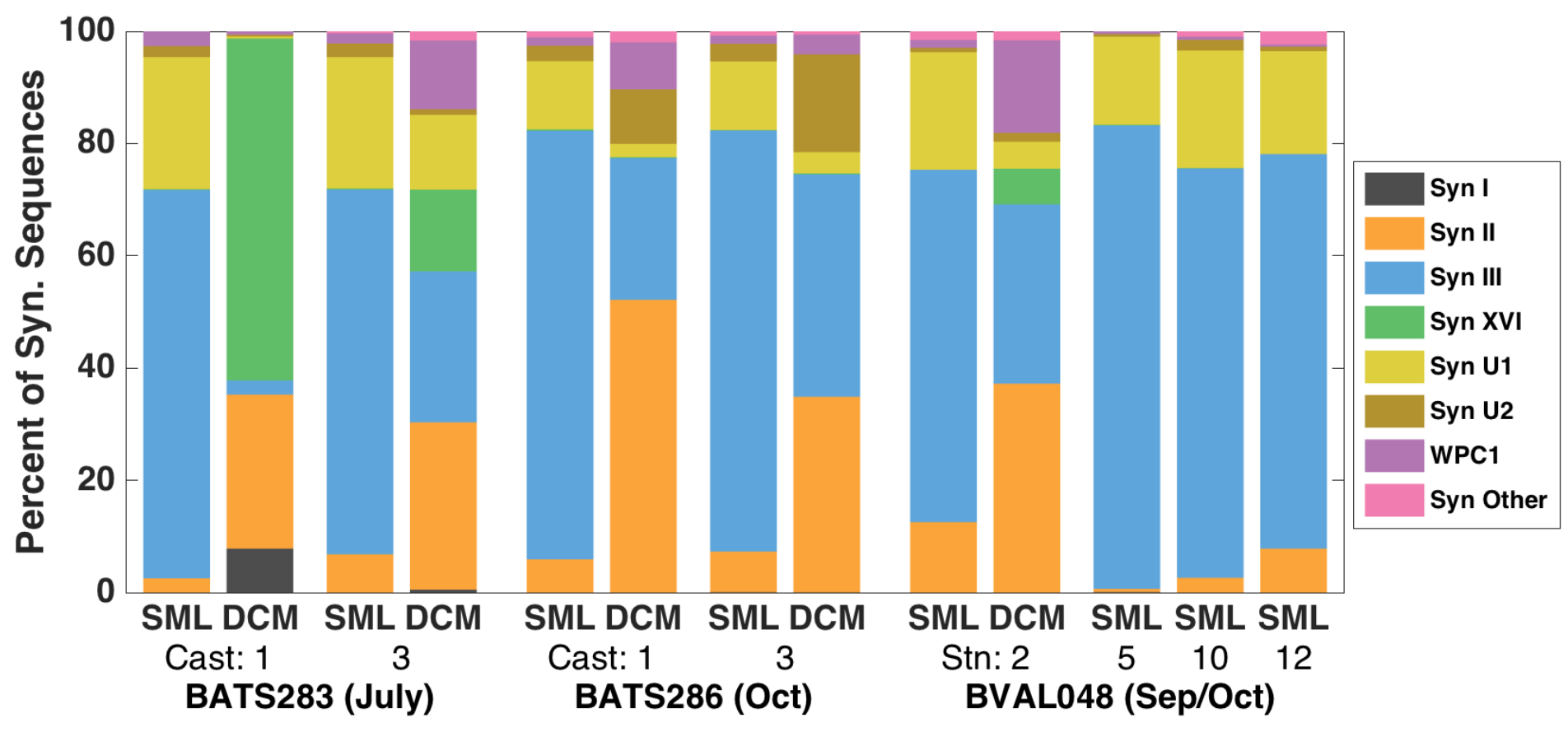

Figure 4: Synechococcus operational taxonomic unit (OTU) contributions by various identified, cultured clades (Mazard et al., 2012), and two unnamed clusters (U1 and U2), to surface mixed layer (SML; 5-10m) and deep chlorophyll maximum (DCM; 75-88m) communities. 